\section{BIOCLIMATOLOGY AND BIOMETEOROLOGY}

$\mathrm{T}$

HE International Society for Bioclimatology and Biometeorology, which was founded in 1956 for the purpose of bringing together all kinds of people interested in the effects of climate on life, held its first congress in Vienna during September 23-27. The congress was attended by about one hundred. scientists from most parts of the world, and it provided an opportunity for set talks on selected topics, short communications and lively discussions.

One of the aspects of climate which has been so far little-understood is ionization of the atmosphere. The term itself is vague, and it was obvious that ionization could mean cosmic rays, or normal components of the air electrically charged, or small suspended particles of the order of $0.1 \mu$ in diameter which can be detected by their electrical charges, or even ordinary dust. Experiments to study how specific sensations are related to ionization are difficult to control, but some work in the United States has suggested that sensations of 'stuffiness' in rooms are connected with ionization of the air, and good evidence was presented that attacks of bronchial asthma are related not so much to the presence of allergens in the air as to the simultaneous presence of allergens and certain conditions of ionization. Contributions on this subject by Dr. J. C. Beckett, of San Francisco, Dr. I. H. Kornblueh, of the University of Pennsylvania, and Dr. S. W. Tromp, of Leyden, made it seem probable that this may develop into an exciting field of investigation, not into an outlet for cranks smelling electricity.

Zoologists and botanists are becoming increasingly concerned with microclimate and its effects on life. Thus the temperature, humidity, air movement and heat radiation near the ground can be so widely different from conditions prevailing near the tree-tops in a forest that it is useless to consider only the climate of a forest as a whole, and microclimate must be studied in detail. Dr. R. B. Platt, of Emory University, Georgia, provided data about gradients of temperature and humidity in woods and in open fields, and Dr. V. Pasak, from Czechoslovakia, presented evidence that weeds growing in neglected woodlands interfere with the growth of new trees by their unfavourable effects on the microclimate near the soil. Outstanding among the zoologists' contributions was a well-illustrated account by Dr. R. C. Rainey, of London, of locust migration in Africa, which showed that the only relevant factor in directing locusts towards one area or another is the wind, while the insects in the swarm fly about apparently aimlessly and in circles. Another valuable contribution originating in Africa was that of Dr. Cloudsley-Thompson, of the Department of Zoology, King's College, London, who has studied the behaviour of some terrestrial arthropods which, like woodlice, lose water easily, and who produced evidence that the habits and habitats of such arthropods are related to their needs for preserving body water.

The tremendous possibilities for bioclimatological studies in tropical veterinary medicine were skilfully reviewed by Dr. J. D. Findlay, of Ayr, Scotland, who showed how milk yields could suffer at high temperatures and described some of the physiological work carried out at the Hannah Dairy Research Institute in Ayr, while another stimulating talk by Dr. R. Koller, from Austria, reviewed the problem in relation to animal husbandry in a tem. perate country with a cold winter and concluded that cattle did better, on the whole, in stables than out of doors when the weather was cool.

A particularly valuable aspect of such a conference is the possibility of discussing intricate problems which have a bearing on several fields of research. Town planning in relation to climate is such a problem, and outstanding contributions about this came from Dr. Vigan, of France, who discussed plans for workers' cities being built in the Sahara, and from Mr. Page, of the University of Liverpool, who surveyed problems of environmental comfort in houses not only from the engineering, physiological and æsthetic aspects, but also in relation to what is considered comfortable by different people. An interesting point made by Dr. Vigan, in reply to a question, was that trapical neuroses are infrequent among workers in the Sahara; this he attributed to the fact that the workers were there to do a useful job (though this could be connected with the fact that the weather in the Sahara is less uniformly warm than in equatorial regions, where neuroses are common).

The problem of adaptation to environment was approached in several ways. Prof. Pichotka, of Germany, showed not only that slices of potato metabolized at a lower rate in a cool medium than in a warm one, but also that they continued at a lower metabolic rate after leaving the cool medium, or at a higher rate after leaving the warm medium. This was particularly interesting, because these findings, obtained in cross-over experiments, resembled similarly crossed-over data obtained in mice and men and presented by Dr. J. S. Weiner, of the Medical Research Council Climate and Working Efficiency Laboratories, Oxford, who showed, among other things, that mice reared in a hot environment survive heat stress better than those reared in a temperate one. Though some adaptations, especially those in potato slices, must be brought about by changes in enzyme systems, the central nervous system appears to play a fundamental part in adaptation to climate in man, and evidence about this was presented by Dr. E. M. Glaser, of the London Hospital Medical College. Other evidence which implied the existence of central nervous adaptation came from Dr. H. Jungmann, of Germany, and Dr. M. Halhuber, of Austria, who had jointly studied acclimatization in the Alps at moderately high altitudes.

When considering the general effects of weather on health and sensations, speakers were perhaps on slightly more shaky ground, and this was forcibly pointed out by several speakers, including Prof. $H$. Berg, of Germany, one of the vice-presidents of the Society. Statistical evidence was produced, for example, that certain conditions, such as emboli of the heart, are more frequent in some than in other kinds of weather, but both the material and its statistical treatment were inconsistent, and the very definitions of the weather with which the clinical findings have been correlated were unsatisfactory. This branch of bioclimatology suffers, more than any other, from obscure terminology and meaningless notions such as 'sensitivity to weather' (Wetterfühligkeit), 'vagotonia' or 'meteorological fronts'. But the congress did some good in discouraging notions or lines of research which are unintelligible 
without an excess of imagination. One of the most valuable aspects of the congress was that it provided an opportunity of revising fundamental notions borrowed from other branches of science which have been modified or invalidated by recent work.

The chairman of the congress was Dr. Fred Sargent, professor of physiology in the University of Illinois (who is now spending one year at the Medical Research Council Climate and Working Efficiency Research Unit in Oxford). Dr. J. L. Cloudsley-Thompson, of the Department of Zoology, King's College, London, was elected to the Council of the Society. The Society has begun publishing the International Journal of Bioclimatology and Biometeorology, and the proceedings of its first congress will appear in that journal. The second international congress of bioclimatology will be held in 1960, and England and Scotland have been mentioned as possible places for it. Information about the Society can be obtained from its secretary, Dr. S. W. Tromp, Hofbrouckerlaan 54, Oegstgeest, Leyden, Holland, or from its representative in Great Britain, Dr. E. M. Glaser, Department of Physiology, London Hospital Medical College, Turner Street, E.1. Candidates for election must be actively engaged in some field of bioclimatology or biometeorology, they must be proposed by two members, and they must be approved by the Council. The business of the Society is transacted mostly in English.

E. M. Glaser

\section{TRANSISTOR TECHNOLOGY}

A

CONFERENCE on transistors, organized by the Electronics Group of the Institute of Physics, was held at the Brunel College of Technology, Acton, during September 27-28.

In almost every field of endeavour, the rate of progress largely depends on the facilities that exist for discussion and for exchanging information. This is particularly true when the available resources are scattered over a large number of industries, government and educational organizations, as is the case with the work on transistors. In the United States, professional societies and educational establishments seem to delight in organizing symposia and conferences, whereas in Britain there appears to be less inclination for activities of this kind; one hopes, therefore, that the success of this conference will provide a suitable stimulus to others.

Dr. M. E. Haine, chairman of the Electronics Group, explained that the topics had been chosen in such a way as to provide a broad picture of the wide range of activities that are embraced by transistor technology. Thus, the conference was less concerned with thrashing out points of detail than with providing an opportunity for those who are concerned with the details themselves to see a general picture.

The first paper, on "The Effect of Physical Proper. ties of a Semiconductor on Device Characteristics", was given by Mr. D. D. Jones (General Electric Co.). In discussing the high-frequency performance of alloy transistors, he showed that the mobilities of both the majority and the minority carriers must be taken into account ; the relative merits of $n-p-n$ and $p-n-p$ structures largely depend on the degree of avalanche multiplication that is characteristic of the carrier- depletion regions of thin collector junctions. Mr. Jones indicated which physical properties are important in the design of high-speed switching tran. sistors and of power transistors. He also discussed the relative merits of germanium and silicon as transistor materials.

In the next paper, Dr. W. Bardsley (Royal Radar Establishment) discussed "Defocts in Transistor Materials", and, in particular, mentioned the effects of chemical impurities, particle bombardment, and dislocations in the crystal structure. A typical chemical defect, that can have a marked effect on the electrical performance of the semiconductor, is the presence of oxygen in silicon. Defects created by particle bombardment, for example, by means of neutrons, can often be removed by annealing. Dr. Bardsley described various techniques, such as etching and the use of X-rays, for revealing the presence of dislocations in crystals. Finally, he spoke of interactions between defects; thus interactions between dislocations and oxygen content can affect the heat treatment properties of silicon.

Mr. J. G. Cressell (Marconi) opened his paper on "Power Transistors" by recounting the main steps by which progress has been made in this field. First, there was Webster's analysis of the variation of current gain with emitter current, which showed how emitter efficiency, bulk recombination and surface recombination play their part. The development of new alloys to give high emitter efficiency and of techniques to produce thin base regions were two practical steps of major importance. Fletcher's study of the transverse field in the base region led to a reconsideration of the optimum geometrical arrangement. Mr. Cressell then described how both carrier life-time and surface recombination velocity can show substantial variations with emitter current, and how these effects become important in high-power transistors.

The design of high-frequency transistors presents a considerable challenge. In describing "A New High-frequency Germanium Transistor", Mr. J. S. Lamming (General Electric Co.) first discussed the principle of Kroemer's drift transistor; in this 8 gradation in the conductivity of the base region creates a drift field which reduces the transit-time for minority carriers. One of the most attractive ways of producing a graded base region is to diffuse the impurity atoms into the region. In Mr. Lamming's technique of 'post-alloy diffusion' the emitter is alloyed on to a base region of uniform conductivity. The emitter alloy is made to contain known quantities of $p$ and $n$ impurities, the segregation and diffusion coefficients of which are carefully chosen. After alloying, the emitter is $p$-type. The structure is then heated to such a temperature that diffusion takes place, the coefficients being such that the diffusion is predominantly that of the $n$ impurities. This technique enables very narrow base regions, with the desired gradation of conductivity, to be achieved.

Dr. J. T. Kendell (Texas Instruments) reviewed the situation of "Silicon Transistors". He mentioned how the difficulty in producing silicon of adequate purity and of keeping it pure during subsequent processing had delayed the development of these devices. The alloy process, so successful with germanium, had proved difficult with silicon and, as a result, most of the progress has been achieved with other processes, such as double-doping during crystal 